\title{
Pensamento Computacional: Uma Proposta de Oficina Para a Formação de Professores
}

\author{
Paulo Antonio Pasqual Júnior - UCS - papjunior@ucs.br \\ Simone de Oliveira - UCS - soliveira8@ucs.br
}

\begin{abstract}
Resumo: O ensino de programação e o desenvolvimento do pensamento computacional estão sendo adotados em diversas escolas no Brasil e no mundo, abrindo espaço para a discussão da formação de professores nesse contexto. Este artigo tem como objetivo apresentar uma proposta de oficina introdutória para a formação de professores, tendo sido realizado por meio de um estudo de caso, com natureza qualitativa. Como método, foi utilizada a observação do participante e a aplicação de dois questionários em uma oficina de formação de professores. A análise dos dados se deu com a escolha da análise de discurso para as questões abertas e com análise estatística descritiva para as questões quantitativas. Os resultados da investigação revelaram que os professores, em sua maioria, desconhecem a temática e, consequentemente, apresentam dificuldades em reconhecer a importância do uso do PC.
\end{abstract}

Palavras-chave: Pensamento Computacional. Formação de Professores. Programação Visual.

\section{Computational Thinking: A Workshop Proposal for Teacher Training}

\begin{abstract}
The teaching of programming and the development of computational thinking are being adopted in several schools in Brazil and in the world, opening space for the discussion of teacher training in this context. In this bias, this article aims to present a proposal for an introductory workshop for teacher training, having been carried out through a case study, with a qualitative nature. As a method, the observation of the participant and the application of two questionnaires were used in a teacher training workshop. The analysis of the data occurred with the choice of discourse analysis for the open questions and with descriptive statistical analysis for the quantitative questions. The results of the investigation revealed that the majority of teachers are unfamiliar with the subject and, therefore, have difficulties in recognizing the importance of using the PC.
\end{abstract}

Keywords: Computational Thinking. Teacher training. Visual programming.

\section{Introdução}

As iniciativas para o estudo de programação nas escolas de ensino básico têm sido objeto de estudo de pesquisadores por mais de 40 anos. Seymour Papert (1980) foi pioneiro no que se refere a pensar uma linguagem de programação que pudesse ser ensinada para todos e que auxiliasse no desenvolvimento do aprendizado de outras ciências. Principalmente, a partir dos anos 1980, diversos países iniciaram a implementação de iniciativas e políticas públicas para o estudo de programação em escolas de ensino básico (Valente, 1999).

No Brasil, algumas iniciativas isoladas trouxeram a linguagem criada por Papert para o cenário escolar, permitindo que as crianças, no final da década de 1980, pudessem começar a aprender programação por meio da manipulação de uma tartaruga virtual. Papert (1980) tinha uma visão inovadora para seu tempo e, ao conceber a Linguagem LOGO, acreditava que as crianças, além de aprenderem os conceitos de programação, poderiam desenvolver habilidades matemáticas e de outras ciências de forma natural.

Contudo, por muito tempo, essas ideias estiveram adormecidas, uma vez que a informática educativa passou a utilizar os novos softwares que emergiram com as tecnologias do século XXI. Para Valente (2016), o fato de as novas tecnologias serem mais interessantes do que as linguagens de programação fez com que o uso da linguagem LOGO ficasse apenas no passado.

Por outro lado, recentemente a chama do ensino de programação se reacendeu. 
Teóricos da computação e da Informática na Educação têm defendido a ideia de que as habilidades de programação e as competências dos cientistas da computação são necessárias para todos no século XXI. Jeannet Wing (2016) chamou esses conhecimentos de "Pensamento Computacional" (PC), um conjunto de habilidades que humanos e máquinas possuem juntamente para a resolução de problemas complexos. Brennan e Resnick (2012) definem o termo em três grandes dimensões. São elas: conceitos que englobam sequência, repetição, condição, eventos, paralelismo, operadores e dados; práticas relativas ao pensamento incremental e interativo, testes e depuração, abstração, reutilização e modularização e, por fim, as perspectivas que se referem à expressão, conexão e ao questionamento.

Nesse contexto, é necessário apresentar alguns desafios que fazem parte do atual cenário brasileiro. Um deles perpassa pelo currículo escolar, o qual, infelizmente, em grande parte, não considera o PC como uma de suas competências, apesar de haver diversas menções sobre o pensamento computacional publicadas na versão final da Base Nacional Comum Curricular (BNCC), que propõe as dez competências gerais que devem fazer parte dos componentes curriculares da educação básica. O texto relata a prática pedagógica da cultura digital, como: "Utilizar tecnologias digitais de comunicação e informação de forma crítica, significativa, reflexiva e ética nas diversas práticas do cotidiano (incluindo as escolares) ao se comunicar, acessar e disseminar informações, produzir conhecimentos e resolver problemas" (MEC, 2018). Koscianski e Glizt (2017) argumentam que apesar de atividades envolvendo raciocínio lógico fazerem parte de diversas áreas do conhecimento, o pensamento computacional não é tratado como uma competência prioritária a ser desenvolvida durante o ensino básico.

O ensino do Pensamento Computacional dentro da perspectiva educacional tem provocado discussões em âmbito mundial sobre as possibilidades de alteração do currículo escolar de várias maneiras, seja por meio da inclusão do pensamento computacional como uma disciplina ou como uma competência transversal às outras disciplinas da educação básica. No Brasil, essas iniciativas estão começando a movimentar-se, principalmente em escolas privadas, diferentemente da Inglaterra, por exemplo, que dispõe de uma política pública voltada à disseminação das competências da Ciência da Computação no currículo da educação básica (Valente, 2016).

Diante dessa realidade, faz-se necessário pensar a formação do professor para atuação com o PC. De acordo Araujo, Andrade e Guerrero (2015), os conceitos de Pensamento Computacional são pouco conhecidos dentre os profissionais e acadêmicos da computação no Brasil. O estudo de Farias, Andrade e Alencar (2015) traz evidências de que os egressos dos cursos de Licenciatura em Computação também não possuem clareza conceitual acerca do Pensamento Computacional, necessário para a atuação docente.

A partir da perspectiva apresentada, é relevante que a prática pedagógica possa ser constantemente pensada, tendo como suporte uma epistemologia e saberes com premissas pautadas na construção do conhecimento na prática vivenciada do estudante em que o sujeito mostra-se ativo no processo de aprendizagem. Com isso, entende-se que é essencial proporcionar aos professores a oferta de cursos de formação, capacitação ou oficinas que evidenciem a importância das tecnologias digitais, bem como a reflexão sobre as possibilidades de aplicação para o processo de ensino e de aprendizagem na educação básica no percurso dos currículos (Sonego et al, 2018).

Corroborando esse cenário, Souza, Rodrigues e Andrade (2016), em um estudo sobre o ensino de robótica, concluíram que, embora as oficinas de robótica tenham se popularizado em algumas escolas do Brasil, os professores das disciplinas regulares do currículo, bem como os alunos, apresentam baixo rendimento na programação de Robôs 
em virtude de um déficit conceitual acerca do Pensamento Computacional.

Dessa forma, entende-se que um processo de construção de uma proposta de formação de professores deverá utilizar computadores e dispositivos digitais na prática para contribuir e minimizar as resistências ou dificuldades apresentadas. Para isso, uma ação interessante, que poderá fazer parte do planejamento da formação, é a utilização da mineração de dados, com o intuito de traçar um perfil mais detalhado desses professores, verificando suas dificuldades, preferências, conhecimentos e tendências no uso das tecnologias digitais. O mapeamento dessas informações contribui para que, no futuro, novas ferramentas tecnológicas possam ser desenvolvidas para auxiliar professores, otimizando e tornando o trabalho mais assertivo, conectado com os anseios dos sujeitos envolvidos, seja professores ou alunos, e da própria sociedade como um todo. Através do estudo de perfil docente, será possível planejar atividades com proposição de alternativas concretas que visam à qualificação das ações desenvolvidas por professores em suas escolas, utilizando as tecnologias digitais disponíveis para esse fim (Machado et al, 2018).

Nesse contexto, os desafios do ensino do PC na educação básica vão desde a formação inicial e continuada de professores até a seleção de um currículo que contemple os conceitos e práticas da Ciência da Computação. Os trabalhos de Farias, Andrade e Alencar (2015), Barcelos et al. (2015) e Barcelos, Bortoletto e Andriolli (2016) apontam que, embora haja um crescimento de discussões nesse campo, ainda são poucas as investigações que se dedicam a discutir a formação inicial e continuada de professores em âmbito nacional. Sendo assim, este artigo apresenta uma oficina de formação de professores no âmbito do PC e busca discutir a situação do conhecimento acerca do termo por professores da rede pública de uma escola na região da serra gaúcha. Outros trabalhos como os de Barros et. al (2018) têm apontado para as diversas possibilidades de formação de professores no campo do $\mathrm{PC}$ e a necessidade de novas experiências neste campo.

\section{Procedimentos metodológicos}

Diversos países têm implementado iniciativas para integrar a Ciência da Computação e o Pensamento computacional na sala de aula. Contudo, muitas vezes, essas iniciativas não promovem efetivamente mudanças na prática escolar ou na forma como se ensina ou se aprende. Uma discussão antiga no campo da informática na educação, iniciada ainda com Papert (1980), refuta o instrucionismo com o qual a computação tende a ser adicionada nos currículos escolares. Do mesmo modo, atualmente as reestruturações e a adição ou modificação das disciplinas de Ciência da Computação nas Universidades não trazem inovação, pois é geralmente adicionada uma nova disciplina ou essas competências são trabalhadas em oficinas extracurriculares (Valente, 2016).

Nesse contexto, em que, cada vez mais, a Ciência da Computação e o Pensamento Computacional têm aparecido como protagonistas de um ensino e aprendizagem para o cidadão do século XXI convêm discutir questões relativas à formação de professores, levando em consideração que o professor e as concepções de ensino e de aprendizagem são fundamentais para o rompimento das culturas pertinentes à transmissão de saberes. Assim, este artigo apresenta um estudo de caso, de natureza qualitativa, que se propõe a validar uma oficina de introdução ao pensamento computacional.

A coleta dos dados ocorreu por meio da observação participante durante a oferta da oficina e da aplicação de dois questionários com perguntas abertas e fechadas. A análise dos dados se deu com a escolha da análise de discurso para as perguntas 
abertas e com análise estatística descritiva para as perguntas quantitativas.

A oficina realizada teve duração de oito horas e fez parte de um programa de formação de professores de uma cidade do interior da Serra Gaúcha promovida pela prefeitura, em parceria com uma instituição de ensino superior da região. A cidade é caracterizada por ser pequena, de cultura alemã, tendo 150 professores na rede municipal. Todos os docentes foram inscritos para o programa de formação de professores, sendo que apenas $87(58 \%)$ participaram de pelo menos uma oficina.

Os professores puderam se inscrever livremente em diversas oficinas. A intitulada "Pensamento Computacional" obteve $25(28,7 \%)$ inscritos e teve como foco discutir, em linhas gerais, os seguintes tópicos: histórico do pensamento computacional, estratégias de computação desplugadas e softwares para o desenvolvimento do pensamento computacional.

A oficina foi estruturada da seguinte forma: antes de iniciar os trabalhos, foi realizada uma coleta de dados acerca dos conhecimentos dos professores sobre o tema "Pensamento Computacional". Os participantes foram informados que se tratava de uma pesquisa e foram questionados se estavam de acordo e se concediam o uso dos resultados para fins de investigação científica. Na sequência, os participantes foram convidados a responder um formulário on-line com perguntas apresentadas no Quadro 1 .

\begin{tabular}{|l|l|l|}
\hline & Pergunta & Tipo \\
\hline 1 & Você conhece o termo pensamento computacional? & Múltipla Escolha \\
\hline 2 & Explique o que você entende por pensamento computacional? & Dissertativa \\
\hline 3 & $\begin{array}{l}\text { Qual a sua percepção em relação à necessidade do PC em sala de } \\
\text { aula? }\end{array}$ & Dissertativa \\
\hline 4 & Você já utilizou alguma atividade de PC em sala de aula? & Múltipla Escolha \\
\hline 5 & Quais ferramentas você conhece para o desenvolvimento do PC? & Múltipla Escolha \\
\hline 6 & Você já participou de alguma formação sobre PC & Múltipla Escolha \\
\hline \multicolumn{2}{|r|}{ Quadro 1: Instrumento de Pesquisa Sondagem Inicial } \\
\hline
\end{tabular}

Depois da aplicação do instrumento de pesquisa, foi realizado um diálogo sobre o tema "Histórico do Pensamento Computacional", em que se apresentou a trajetória da construção do conceito a partir dos primeiros escritos de Papert (1980) e dos conceitos recentemente elaborados por Wing (2006, 2008, 2010). Em seguida, foi realizada uma atividade sem o uso do computador, em que os participantes, em grupos previamente estabelecidos, foram convidados a realizar algoritmos em papel, sendo que um dos participantes do grupo foi desafiado a executar o código, em uma espécie de "robô humano". Essa atividade mostrou-se importante, pois permitiu introduzir conceitos de Pensamento Computacional sem a necessidade de um computador e de acesso à internet. Esse tipo de atividade de computação desplugada se baseia em propostas como as de Bell, Witten e Follows (2011).

Na sequência, foram realizadas atividades utilizando as plataformas Code.org e Scratch. Inicialmente, utilizaram-se os tutoriais "A Hora do Código", cuja finalidade é possibilitar uma primeira experiência de solução de problemas, utilizando a programação em blocos. A partir da experimentação pelos professores, foram discutidas 
questões que aproximaram as atividades da Hora do Código da Code.org com a de computação desplugada realizada na etapa anterior.

Como sequência da proposta, os professores tiveram a oportunidade de fazer um cadastro na plataforma Scratch, realizando uma exploração inicial. A partir disso, os participantes puderam perceber as relações entre as atividades realizadas, a semelhança entre os blocos de programação da Code e a possibilidade de livre criação. Como proposta de trabalho no Scratch, foi desenvolvido um pequeno game de coletar. Assim, os professores puderam ter contato com as principais estruturas de programação disponíveis na ferramenta.

Uma das habilidades exercitadas com a utilização do Scratch é a ação e reflexão sobre a ação, permitindo que os professores testem as suas hipóteses ao realizarem um determinado procedimento, confrontando os resultados imediatamente a partir do feedback dado. Com isso, o retorno imediato possibilita refletir sobre a ação e, se necessário, realizar a reformulação das hipóteses iniciais para testá-las novamente. Dessa forma, este é um processo em espiral, em que se podem perceber, nas representações nos códigos, as descrições do pensamento e os diversos conhecimentos em ação (Ventorini, 2018).

Como parte final da atividade, foi feito um debate entre os participantes, com intuito de retomar alguns conceitos trabalhados na oficina e também estimular os professores para buscarem aprender mais sobre o tema. Dessa forma, a oficina foi organizada com a seguinte estrutura:

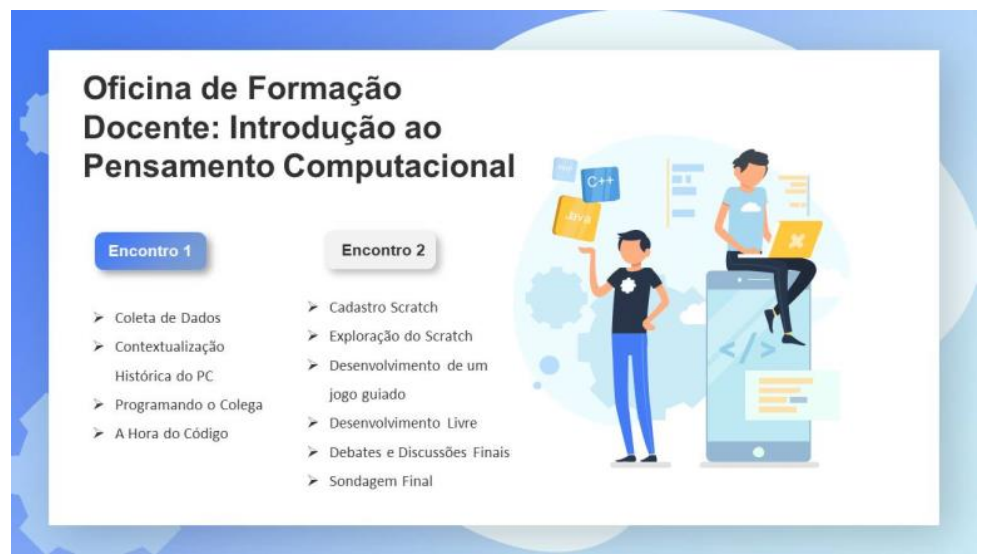

Fig. 01: Estrutura de Oferta da Oficina de PC Fonte: Autores

Na sequência, os participantes foram convidados a responder à segunda parte da pesquisa on-line. As perguntas realizadas estão expressas no quadro 2:

\begin{tabular}{|l|l|l|}
\hline & Pergunta & Tipo \\
\hline 1 & Explique o que você entende por pensamento computacional? & Dissertativa \\
\hline 2 & Qual a sua percepção em relação à necessidade do PC em sala de aula? & $\begin{array}{l}\text { Múltipla } \\
\text { Escolha }\end{array}$ \\
\hline 3 & $\begin{array}{l}\text { Você pretende utilizar as atividades com pensamento computacional } \\
\text { em sala de aula? }\end{array}$ & $\begin{array}{l}\text { Múltipla } \\
\text { Escolha }\end{array}$ \\
\hline 4 & $\begin{array}{l}\text { Como você avalia a oficina de PC? } \\
\text { Eúltipla } \\
\text { Escolha }\end{array}$ \\
\hline 5 & $\begin{array}{l}\text { Em que formato de aula você pretende utilizar os conhecimentos } \\
\text { trabalhados na oficina. }\end{array}$ & $\begin{array}{l}\text { Múltipla } \\
\text { Escolha }\end{array}$ \\
\hline
\end{tabular}

Quadro 2: Instrumento de Pesquisa Sondagem Final Fonte: Autores 
A partir da sondagem inicial e da sondagem realizada no final da oficina, teve-se o intuito de contrapor algumas questões, buscando evidenciar, em primeiro lugar, a validação da oficina e, em segundo, perceber se os professores atribuíram importância aos assuntos tratados e ainda se as oito horas foram suficientes para gerar mobilizações e modificações nos conceitos acerca do tema.

\section{Resultados, Discussão e Análises}

Nessa oficina de formação docente, a partir dos instrumentos de coleta, foi possível perceber uma série de achados importantes. Os dados estão analisados nesta seção de maneira integrada, buscando contrapor os resultados a partir dos dois instrumentos utilizados. Para fins de organização, usamos a letra $\mathrm{Q}$ seguida do número da questão acompanhado da letra correspondente à sondagem, "a" para o primeiro instrumento e "b" para o segundo, formando a seguinte notação: Q1a, por exemplo.

Em relação à primeira questão Q1a, "Você conhece o termo pensamento computacional?", todos os professores da oficina afirmaram não conhecer o tema, totalizando em 100\% dos participantes. A pergunta seguinte, Q2a, "Explique o que você entende por pensamento computacional", tinha por objetivo investigar, se de alguma forma, esses professores tinham entendimento acerca do tema. Apesar de todos terem respondido na questão anterior que desconheciam o tema PC, uma das respostas se aproximou do conceito e merece destaque "Uma forma de pensar usando linguagem de programação computacional... (chute!) ". Diante disso, é possível perceber a necessidade de investir na formação do professor para prepará-lo, diante da realidade atual e das orientações da BNCC.

Além da formação continuada dos professores, é preciso investir na formação básica. As universidades precisam passar por um processo de reformulação dos seus currículos que respondam às necessidades dos tempos atuais, diante da perspectiva de transformações e evoluções tecnológicas constantes.

A mesma questão citada anteriormente, Q1b, repete-se no formulário dois e tem por objetivo investigar se os conceitos trabalhados na oficina foram assimilados pelos professores. A questão correspondente no formulário dois foi a Q2b e evidenciou uma significativa melhora em relação à primeira sondagem. Enquanto na primeira questão apenas um professor se aproximou de uma resposta que poderia ser considerada coerente, na segunda sondagem, $65 \%$ das respostas poderiam ser consideradas próximas do conceito de pensamento computacional. Cabe destacar o registro de um dos professores participantes:

Uma forma de desenvolver raciocínios que possibilita o desenvolvimento de sequências lógicas e, consequentemente, o desenvolvimento de programas que podem possibilitar a realização das mais variadas tarefas, inclusive relacionadas à aprendizagem.

É importante ressaltar que, apesar da oficina ser relativamente curta, os professores conseguiram, de alguma forma, construir uma ideia mais próxima do conceito de Pensamento Computacional.

Cabe destacar também a questão Q3a e a sua correspondente Q2b, relativas à percepção dos professores e à necessidade do uso do pensamento computacional em sala de aula como estratégia de ensino e de aprendizagem. Na primeira sondagem, 
$66,7 \%$ dos participantes responderam que não tinham uma opinião formada sobre o assunto, enquanto $33,3 \%$ definiram o pensamento computacional na sala de aula como razoavelmente importante.

$\mathrm{Na}$ coleta final, contudo, os resultados apontaram para uma melhor aceitação da necessidade do PC na escola. 72,7\% dos participantes considerou o tema muito importante para a sala de aula, enquanto $27,3 \%$ consideraram razoavelmente importante. Nesse caminho, a questão Q3a evidenciou que, pelo fato de os professores desconhecerem o assunto, nenhum dos participantes havia utilizado alguma atividade de PC em sala de aula, embora a questão seguinte tenha mostrado que 13,3\% dos participantes já havia ouvido falar do Scratch. O desconhecimento do conceito, como também de ferramentas para o desenvolvimento do PC, evidencia-se na questão Q6a, pois $100 \%$ dos professores afirmaram não ter participado de nenhum tipo de formação relacionada ao tema até o presente momento.

Com o intuito de validar a oficina, a questão Q3b buscou avaliar se os professores pretendiam utilizar o PC em sala de aula. Assim, 90,9\% dos praticantes responderam que pretendem utilizar o pensamento computacional em sala de aula, enquanto $9,1 \%$ responderam que não pretendem.

A questão Q4b buscou avaliar a satisfação dos professores participantes, sendo que $54,5 \%$ deles avaliaram a oficina como "Muito boa", enquanto 45,5\% avaliaram como ótima. Por fim, uma última questão buscou entender como o professor utilizaria o PC em sala de aula. Como opções havia: a) "Usar tutoriais Hora do Código e deixar que os alunos sigam" e b) "Utilizar situações problema em que os alunos possam explorar e criar utilizando softwares para o desenvolvimento do PC" e um espaço para outras considerações. Como resposta obteve-se $63,6 \%$ para a alternativa "a" e $36,4 \%$ para a alternativa "b".

Esta última questão merece destaque, pois versa sobre a epistemologia. Enquanto usar tutoriais remete a uma perspectiva instrucionista, usar situações problema e deixar que os alunos explorem se aproxima de uma possibilidade construcionista. Mesmo que a oficina tenha privilegiado teoricamente o uso do pensamento computacional baseado no construcionismo de Papert (2008), a maior parte dos professores ainda utilizaria esses recursos de forma oposta. Nesse sentido, evidencia-se a necessidade de processos de formação, que privilegiem o estudo das concepções de ensino/aprendizagem focando em perspectivas que se distanciem da simples instrução.

\section{Considerações Finais}

Este artigo buscou apresentar uma proposta de oficina de pensamento computacional voltada à formação de professores, ao mesmo tempo em que se preocupou em destacar a importância do estudo sobre a temática. Conclui-se que, de certa forma, para os professores que possuem formação na área de educação e tecnologia, é mais fácil transitar e se adaptar ao uso do PC nas práticas de sala de aula. No entanto, quando se trata da formação básica ou continuada da maioria dos professores, das mais diferentes áreas do conhecimento, da Educação Infantil ao Ensino Médio, a realidade é extremamente difícil por diversos fatores, e a grande maioria dos professores não sabe como utilizar o PC e desconhece as suas possibilidades de contribuições cognitivas.

Uma oportunidade de uso do PC nas escolas de educação básica é a aplicabilidade no contexto da transversalidade, perpassando mais de uma disciplina na perspectiva da interdisciplinaridade. Uma alternativa para essa proposta é a metodologia de projetos, seja projetos de ensino ou de aprendizagem. 
Ademais, é relevante ressaltar que, para desenvolvermos projetos interdisciplinares com uso do PC, um dos fatores essenciais desse processo é a capacitação dos professores, a partir do uso das inúmeras possibilidades analógicas ou digitais que fazem parte da concepção de resolução de problemas simples ou complexos.

A importância dessa necessidade se comprova nas sondagens realizadas durante o caso apresentado neste artigo. Cabe salientar que, na primeira sondagem, os professores, em sua maioria, não conheciam os conceitos de PC e, portanto, consideraram esses saberes pouco relevantes para o âmbito da sala de aula. Contudo, após as $8 \mathrm{~h}$ de formação, ficou evidente que os professores ressignificaram os conceitos e a aplicação do PC na sala de aula. Diante disso, torna-se evidente o fato de, mesmo com a oficina de apenas $8 \mathrm{~h}$, ter sido possível sensibilizar os professores para a importância da introdução do PC no cotidiano escolar e de se desenvolver essas competências no ensino básico.

Além disso, este estudo valida um modelo uma oficina introdutória de PC para professores que mescla discussões conceituais, dinâmicas com atividades desplugadas e prática com programação em blocos, a qual pode ser utilizada como inspiração para outros professores formadores.

Assim, podemos dizer que este modelo pode ser replicado, pois atingiu o objetivo de, por um lado, inquietar o professor para utilizar esses conceitos no cotidiano escolar e, por outro, buscar novos saberes que podem se inter-relacionar com as diversas áreas do conhecimento no cotidiano escolar.

\section{Referências}

ARAUJO, A.L.S.d.; ANDRADE, W. L.; GUERRERO, D.D.S. Pensamento

Computacional sob a visão dos profissionais da computação: uma discussão sobre conceitos e habilidades. In: CONGRESSO BRASILEIRO DE INFORMÁTICA NA EDUCAÇÃO, 4., 2015, Maceió. Anais do Congresso Brasileiro de Informática na Educação. Maceió: CBIE 2015. 10 p. Disponível em: <http://www.brie.org/pub/index.php/wcbie/article/view/6329/4438>. Acesso em: 20 mar. 2019.

BARCELOS, T; BORTOLETTO, R; ANDRIOLI, M.G. Formação online para o desenvolvimento do Pensamento Computacional em professores de Matemática. In: CONGRESSO BRASILEIRO DE INFORMÁTICA NA EDUCAÇÃO, 5., 2016, Uberlândia. Anais dos Workshops do V Congresso Brasileiro de Informática na Educação. Uberlândia: CBIE, 2016. p. 1228 - 1237. Disponível em: <http://brie.org/pub/index.php/wcbie/article/view/7048/4922>. Acesso em: 5 dez. 2016.

BARROS, T.T.T; REATEGUI, E.B.; MEIRA, R.R.; TEIXEIRA, A.C.T. Avaliando a Formação de Professores no Contexto do Pensamento Computacional. RENOTE Revista Novas Tecnologias na Educação. Universidade Federal do Rio Grande do Sul (UFRGS), Volume. 16, n. 2, p.1-10, Porto Alegre: 2018.

KOSCIANSKI, A.; GLIZT, F. R. O pensamento computacional nos anos iniciais do Ensino Fundamental. RENOTE - Revista Novas Tecnologias na Educação.

Universidade Federal do Rio Grande do Sul (UFRGS), Porto Alegre, v. 15, n. 2, p.1-10, 20 maio 2019 
BELL, T; WITTEN, I. H.; FELLOWS, M. Computação Unplugged: Ensinando Ciência da Computação sem o uso do computador. [salvador]: Desconhecido., 2011. Disponível em: <https://classic.csunplugged.org/wpcontent/uploads/2014/12/CSUnpluggedTeachers-portuguese-brazil-feb-2011.pdf $>$. Acesso em: 03 abr. 2019.

BRENNAN, K.; RESNICK, M. New frameworks for studying and assessing the development of computational thinking. 2012. Disponível em: $<$ http://web.media.mit.edu/ kbrennan/files/Brennan_Resnick_AERA2012_CT.pdf $>$. Acesso em: 10 mai. 2019.

FARIAS, A. B.; ANDRADE, W. L.; ALENCAR, R A. Pensamento Computacional em Sala de Aula: Desafios, Possibilidades e a Formação Docente. In: CONGRESSO BRASILEIRO DE INFORMÁTICA NA EDUCAÇÃO, 4., 2015, Maceió. Anais dos Workshops do IV CBIE. Maceió: CBIE, 2015. v. 1235, p. 1226 - 1235. Disponível em: $<$ http://www.br-ie.org/pub/index.php/wcbie/article/view/6262/4384>. Acesso em: 05 mai. 2019

KOSCIANSKI, A.; GLIZT, F. R. O pensamento computacional nos anos iniciais do Ensino Fundamental. RENOTE - Revista Novas Tecnologias na Educação. Universidade Federal do Rio Grande do Sul (UFRGS), Volume 15, n. 2, Porto Alegre:2017

MACHADO, G. B.; KUHN, I; SANTOS, F. D.; WIVES, L. K. Um estudo sobre o perfil de professores do ensino fundamental e o uso de tecnologias para a educação: uma proposição de agenda de pesquisa a partir de dados educacionais. RENOTE - Revista Novas Tecnologias na Educação. Universidade Federal do Rio Grande do Sul (UFRGS). Volume 16, nº 2, Porto Alegre: 2018.

PAPERT, S. A máquina das crianças: repensando a escola na era da informática. Porto Alegre: Artmed, 2008.

PAPERT, S. Mindstorms: Children, Computers and Powerful Ideas. New York: Basic Books, 1980.

SONEGO, A.H.S.; RIBEIRO, A.C.; MACHADO, L.R.; BEHAR, P. Formação de professores: uma arquitetura pedagógica com foco na m-learning. RENOTE - Revista Novas Tecnologias na Educação. Universidade Federal do Rio Grande do Sul (UFRGS). Volume 16, nº 2, Porto Alegre: 2018.

SOUZA, I.M. L.; RODRIGUES, R.S.; ANDRADE, W.L. Introdução do Pensamento Computacional na Formação Docente para Ensino de Robótica Educacional. In: CONGRESSO BRASILEIRO DE INFORMÁTICA NA EDUCAÇÃO, 5., 2016, Uberlânida. Anais dos Workshops do V Congresso Brasileiro de Informática na Educação. Uberlândia: CBIE, 2016. p. 1265 - 1274. Disponível em: <http://www.brie.org/pub/index.php/wcbie/article/view/7052/4926>. Acesso em: 10 fev. 2019.

VALENTE, J. (Org.). O Computador na Sociedade do Conhecimento. Campinas: Unicamp/nied, 1999. 
VALENTE, J. Armando. (2016), Integração do Pensamento Computacional no Currículo da Educação Básica: Diferentes Estratégias Usadas e Questões de Formação de Professores e Avaliação do Aluno. Revista e-Curriculum, v.14, n.03, p. $864-897$.

VENTORINI, A.E.; FIOREZE, L. A. Funções e programação no Scratch. RENOTE - Revista Novas Tecnologias na Educação. Universidade Federal do Rio Grande do Sul (UFRGS). Volume 16, nº 2, Porto Alegre: 2018.

WING, J.M. Computational Thinking: What and Why? 2010. Disponível em: $<$ http://www.cs.cmu.edu/ CompThink/resources/TheLinkWing.pdf $>$. Acesso em: 5 out. 2016.

WING, J.M.. Computational Thinking. Communications of The Association For Computing Machinery, [s.1], v. 49, n. 3, p.33-35, mar. 2006.

WING, J. M. Computational thinking and thinking about computing. 2008. Disponível em: < http://rsta.royalsocietypublishing.org/content/366/1881/3717>. Acesso em: 5 mar. 2019. 